\title{
A propósito da noção de “caráter”: as presenças de Kant e Schelling na tese de doutorado de Schopenhauer
}

\author{
By the way of the notion of "character": the presences of Kant \\ and Schelling in the doctoral thesis of Schopenhauer
}

Vilmar Debona

debonavilmar@gmail.com

(Universidade Federal Rural do Rio de Janeiro, Rio de Janeiro, Brasil)

\begin{abstract}
Resumo: 0 presente artigo pretende mostrar como o emprego feito por Schopenhauer das noções de caráter inteligível e de caráter empírico em Sobre a quádrupla raiz do princípio de razão suficiente pode ilustrar a natureza de suas primeiras recepções de Kant e de Schelling.
\end{abstract}

Palavras-chave: Schopenhauer; caráter inteligível; caráter empírico; Kant; Schelling.
Abstract: This paper intends to show as the use carried out by Schopenhauer of the notions of intelligible character and of empirical character in On the fourfold root of the principle of sufficient reason may illustrate the nature of his first reception of Kant and of Schelling.

Keywords: Schopenhauer; intelligible character; empirical character; Kant; Schelling.

DOI: http://dx.doi.org/10.11606/issn.2318-9800.v20i2p67-85

Em uma anotação de 1823, Schopenhauer afirma: "se um dia se dissesse de mim que resolvi o enigma que Kant havia posto, esta seria a minha suprema glória". ${ }^{1} \mathrm{~A}$ declaração pode ser lida em sintonia com a segunda das três exigências apresentadas ao leitor de $O$ mundo como vontade e como representação, no Prefácio de 1818: "a familiaridade com o fenômeno mais importante que ocorreu ao longo dos últimos dois mil anos na filosofia, e que se deu tão perto de nós, a saber, os escritos capitais de Kant"2. Com efeito, a convicção de Schopenhauer de que seu mestre havia procedido

1 SCHOPENHAUER, A. Der Handschriftliche Nachlass. In: Sämtliche Werke. Bd. XI. München: Piper Verlag, 1911-1941, Brieftasche, §23, p.148-149. Salvo indicação contrária, as traduções das citações em alemão são minhas.

2 SCHOPENHAUER, A. O mundo como vontade e como representação. Tomo I. Tradução de Jair Barboza. São Paulo: Unesp, 2005, p.22. As outras duas exigências são as de ler o livro duas vezes e ler a Dissertação Sobre a quádrupla raiz do princípio de razão suficiente (1813), tomando esta última como uma introdução à obra magna. 
com uma “operação de cataratas" naqueles espíritos cegos que se davam o direito a tal procedimento era veemente. Por isso, o próprio Schopenhauer se propôs a colocar um par de “óculos de cataratas" nas mãos dos que obtiveram sucesso na operação; para o uso, porém, a operação seria condição intrínseca ${ }^{3}$. A metáfora utilizada pelo filósofo para se referir ao seu pensamento frente àquele de Kant assenta-se na ideia de que a concepção de "o mundo como representação" seria a mais adequada expressão e, até mesmo, um aperfeiçoamento do fenomenismo kantiano; tratar-seia do único idealismo (pós-kantiano) coerente porque teria limitado o emprego dele à gnoseologia, sem estendê-lo ao domínio ontológico.

No entanto, tais convicções ainda não estavam completamente formadas quando o jovem filósofo, em 1813, elaborou sua tese de doutoramento intitulada Sobre a quádrupla raiz do princípio de razão suficiente: um ensaio filosófico, o que não apenas estimula a refletirmos sobre o peso que as variações de leitura da filosofia kantiana exerce no pensamento schopenhaueriano, mas também a considerarmos que, apresentando-se como único idealismo coerente após Kant, Schopenhauer não deixa de ser influenciado por outros intérpretes do idealismo crítico que são, ao mesmo tempo, alvos de suas ásperas críticas, principalmente Fichte e Schelling. Conforme destacarei, a noção de caráter inteligível, tal como concebida no contexto da Dissertação de 1813 e dos Manuscritos Póstumos dessa época, é também e em grande medida devedora de Schelling. Na primeira edição da Dissertação já encontramos, entretanto, uma crítica - que pode ser considerada amena - ao idealismo transcendental provinda do fato de o pensador acreditar que, nesse período, já teria refletido suficientemente sobre os principais pontos fracos da teoria kantiana do conhecimento. Trata-se de um autor que recentemente havia frequentado (em Göttingen, de 1809 a 1811) as lições de Schulze, de quem havia lido, no Enesidemo (1792), a crítica cética a Kant, mas que filtrara elementos de tal leitura e não deixara de pressupor que a filosofia transcendental era um ponto de partida ineludível. É também de Schulze que, além de acatar o conselho das leituras de Platão e de Kant, colhe a indicação sobre a “inadequada” Dedução transcendental das categorias, assim como sobre as dificuldades de se aceitar a fundamentação da lei de causalidade do exato modo como Kant a propunha.

Ao resolver posicionar-se nos debates filosóficos de sua época, Schopenhauer tem como assunto que mais enaltece sua relação com Kant justamente o conceito de causalidade, desenvolvido, sobretudo, no \$24 de Sobre a quádrupla raiz de 1813, âmbito da primeira modalidade do princípio de razão, a do devir. O conceito de causalidade, além disso, é retomado enquanto lei da motivação na quarta modalidade de tal princípio, paralelamente à primeira consideração pormenorizada dos conceitos de caráter empírico e inteligível. O tema que, neste escrito, mais 
ostentará uma posição intrigante em relação à filosofia kantiana não será a dupla noção de caráter isoladamente, apesar de esta aparecer até mesmo como título do $\$ 46$ (Motivo, decisão, caráter empírico e caráter inteligível), mas especificamente a noção de causalidade. Nesta época, Schopenhauer pressupunha - e é isso que interessa sobremaneira - o caráter inteligível e o caráter empírico nos mesmos termos que Kant e Schelling os concebem:

Kant o definiu - aquilo que está fora do tempo - como caráter inteligível (...) e, na Crítica da razão pura, forneceu uma discussão sobre a diferença entre este e aquele empírico, assim como sobre a complexa relação da liberdade com a natureza (...). Schelling forneceu, no primeiro livro dos seus Escritos ${ }^{4}$, uma apreciável exposição ilustrativa ${ }^{5}$.

O emprego feito por Schopenhauer das noções de caráter inteligível e empírico, assim como de motivo e decisão, teria de ser tomado, em 1813, muito mais sob o viés gnosiológico - a partir da consideração da necessidade que rege todos os fenômenos -, mas não propriamente como noções do âmbito ético. A noção de caráter inteligível, cuja natureza situar-se-ia fora do mundo da necessidade, tal como Kant e Schelling a conceberam, teria de ser tratada como assunto relativo ao âmbito da autêntica

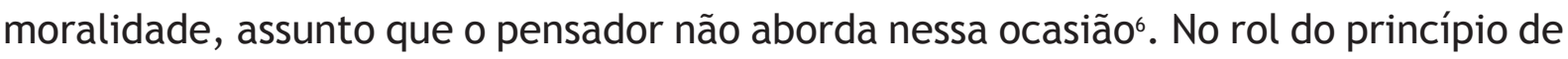
razão, percebe-se como o filósofo restringe-se à indicação de certas atribuições do caráter inteligível, ao passo que se detém no âmbito da causalidade em relação ao caráter empírico, principalmente na medida em que frisa o encontro de um caráter com determinadas motivações, de onde decorrem as ações ${ }^{7}$.

4 Schopenhauer se refere, aqui, aos Philosophische Schriften (1809) de Schelling, no primeiro volume dos quais foram publicadas, pela primeira vez, as Investigações filosóficas sobre a essência da liberdade humana e das questões conexas. Portanto, Schopenhauer cita os Escritos, mas, neste caso, remete-se especificamente ao texto sobre a liberdade.

5 SCHOPENHAUER, A. Über die vierfache Wurzel des Satzes vom zureichenden Grunde. I Auflage. In: Sämtliche Werke. Bd. III. München: Piper Verlag, 1911-1941, §46, p.80, itálicos do autor, negritos meus.

6 Cf. Idem, ibidem.

$7 \mathrm{Na}$ primeira edição de Sobre a quádrupla raiz, ao contrário do que lemos na segunda versão desse escrito (de 1847), Schopenhauer não diferencia a noção de causalidade em três formas diversas, ou seja, entre causa, estímulo e motivo. Esta modificação, referente ao princípio de razão suficiente do devir, é um importante exemplo a partir do qual se pode notar a natureza da variação dos posicionamentos do pensador frente à filosofia kantiana, já que, em 1813, Schopenhauer havia acatado de forma integral a doutrina kantiana das categorias, enquanto que, em 1847, tais categorias são reduzidas a apenas uma - a causalidade - conforme o filósofo já havia exposto detalhadamente na Crítica da filosofia kantiana. Mas a variação quanto a este conceito acontece também no intercurso e entre as produções do próprio Schopenhauer. Assim, se em 1813 o pensador havia adotado a linguagem kantiana quanto ao mencionado conceito, em 1818/19 (em O mundo), as noções de objetidade da Vontade e de corpo não mais permitem uma relação causal entre sujeito do querer e ação; e, em 1847 (mas também em 1839, em Sobre a liberdade da vontade), Schopenhauer particulariza suas três formas de causalidade. Essa tardia especificação é, no entanto, apenas um detalhamento da ideia já presente em $O$ mundo (\$26) segundo a qual cada força da natureza expõe-se com uma certa intensidade enquanto grau de objetivação da Vontade, como o 
Nesse momento da elaboração de seu pensamento, no entanto, Schopenhauer não oferece um tratamento significativamente diferenciado da noção de caráter inteligível - isso seria repetição - em relação à ideia já fornecida na Dialética transcendental kantiana. E aquela “apreciável” (apesar de apenas ilustrativa) exposição de Schelling, de seus Escritos (sobre a liberdade), também pode ser considerada: "remetendo-me a tais obras, tanto aqui como no todo deste ensaio, não tenho a intenção de oferecer uma repetição de assuntos já expostos em outros momentos"8.

Diante disso, duas considerações são particularmente relevantes: ( $\left.1^{\text {a }}\right)$ neste escrito de juventude, reconhecemos, de um lado, as adoções por parte de Schopenhauer não apenas da dupla noção de caráter empírico e inteligível, mas também da cara noção de liberdade tal como Kant e Schelling as concebem; (2 $\left.{ }^{\mathrm{a}}\right)$ de outro lado, a crítica elaborada neste período, apesar de restrita ao âmbito da causalidade, tanto no que respeita à lei de causalidade quanto à lei da motivação, não deixa de ser um prelúdio da censura imediatamente posterior aos poderes da razão kantiana e da paralela abertura à proposta de uma Vontade una que, mesmo sendo metafísica posteriormente ao idealismo crítico, não o teria violado. Assim, ao passo que não desconsidero o imenso espectro de análises e interpretações em torno da ampla relação do pensamento schopenhaueriano em geral com Kant e Schelling, é importante restringir-me, aqui, (i) àquela dupla noção de caráter exposta na Dialética da primeira Crítica, mas somente na medida em que esta foi considerada por Schopenhauer no momento em que elaborava o que podemos denominar de escritos “pré-metafísicos” (em relação à Vontade una). Além disso, também é importante (ii) uma consideração sobre a influência de Schelling especificamente em relação a esta mesma noção de caráter.

caráter do homem ou cada espécie dos reinos inorgânico, orgânico e animal. É na ocasião específica da objetidade de cada um desses fenômenos imediatos da Vontade que a causalidade faz efeito: para o caso da natureza destituída de conhecimento, ela atua como causa ou excitação, para o caso dos animais e do homem, como motivo. Entretanto, na segunda edição da Dissertação e em Sobre a liberdade da vontade, Schopenhauer frisa dois aspectos: (i) principalmente no caso do homem, no encontro de um caráter com um motivo, cujo resultado é a ação, atua o intelecto ou o conhecimento; (ii) a diferença entre causa, estímulo e motivo é apenas a consequência do grau de receptividade de cada ser. "Quanto maior esta for, tanto mais ligeiro pode ser o influxo; a pedra tem de ser arremessada, o homem obedece a um gesto. Mas ambos são movidos por uma causa suficiente, ou seja, com a mesma necessidade. Já que a motivação é simplesmente a causalidade que atravessa o conhecimento, o intelecto é o medium dos motivos porque representa o grau mais alto de receptividade" (SCHOPENHAUER, A. Über die vierfache Wurzel des Satzes vom zureichenden Grunde. II Auflage. In: Sämtliche Werke. Bd. III. München: Piper Verlag, 1911-1941, §20, p.156).

8 SCHOPENHAUER, A. Über die vierfache Wurzel des Satzes vom zureichenden Grunde. I Auflage, §46, p.80, grifo meu. 
O caráter como ato de vontade: a primeira assimilação das noções kantianas de caráter inteligível e empírico

$\mathrm{Na}$ edição de Sobre a quádrupla raiz de 1813, por ter presente o contexto e as definições dadas na terceira antinomia da primeira Crítica kantiana, Schopenhauer considera o caráter empírico como "o modo de agir enquanto pode ser observado" 9 , cujas manifestações fragmentárias acenam para uma unidade e para uma imutabilidade, motivo pelo qual aquele conceito tem de ser pensado como a "aparição de um estado por assim dizer [gleichsam] permanente do sujeito do querer, absolutamente incognoscível, posto fora do tempo" ${ }^{10}$. Este último consistiria no próprio caráter inteligível. Segundo o pensador, seria possível explicar este algo não-temporal com uma imagem caso ele fosse definido como "um ato de vontade universal posto fora do tempo, do qual todos os atos que se dão no tempo seriam apenas o emergir, a aparição"11. E, diante de tal dificuldade, indica como melhor exposição aquela realizada por Kant, que o chamou de caráter inteligível, algo digno da máxima admiração do espírito humano, ao lado da relação, elaborada no mesmo contexto, entre liberdade e natureza. Um dos registros peculiares deste período é o de que Schopenhauer insiste no fato de que o caráter inteligível, além de imutável - pois é tomado como um estado permanente [permanent Zustand] -, jamais pode ser conhecido. O filósofo chega a sugerir que Kant, para designá-lo, pudesse ter usado o termo ininteligível: "teria feito melhor se o tivesse chamado de ininteligível [inintelligible]"12. Ou seja, até este momento Schopenhauer acredita encontrar-se em plena sintonia com a definição kantiana de caráter, e, se chega a sugerir um maior rigor terminológico, é apenas em vista do zelo.

Schopenhauer está considerando, neste ínterim, que para Kant “o ser humano é um dos fenômenos do mundo sensível e, nessa medida, também uma das causas naturais cuja causalidade tem de estar sub leis empíricas. (...) E é ele mesmo, por certo, de um lado fenômeno [Phänomen], de outro - qual seja, em relação a certas certas faculdades - um objeto meramente inteligível"13. 0 importante, então, não é apenas que o homem, enquanto fenômeno do mundo sensível, "possui" um caráter, mas que seu caráter empírico, por estar submetido à lei das motivações e à necessidade, expressa o caráter inteligível, que é livre (ao menos em relação às condições sensíveis). Kant havia escrito:

E assim nós teríamos, em um sujeito do mundo sensível, primeiramente um caráter

9 Idem, ibidem.

10 Idem, ibidem.

11 Idem, ibidem, grifos meus.

12 Idem, ibidem.

13 KANT, I. Crítica da razão pura. Tradução de Fernando Costa Mattos. Petrópolis: Vozes; Bragança Paulista: Ed. São Francisco, 2013, A 546/ B 574, p.436-437, grifos meus. 
empírico, pelo qual suas ações, como fenômenos, estariam em contínua concatenação com outros fenômenos segundo leis constantes da natureza, e poderiam ser deduzidas destes, enquanto condições delas, e assim constituir, em ligação com eles, membros de uma única série da ordem da natureza. Em segundo lugar, também teria de ser concedido a ele um caráter inteligível, que the permitiria ser causa daquelas ações como fenômenos, mas que não estaria ele próprio sob condições da sensibilidade, nem seria ele próprio um fenômeno ${ }^{14}$.

Diante disso, afirmar que Schopenhauer, ao assumir a dupla noção kantiana de caráter nos moldes indicados na Dissertação de 1813, assume também as noções de natureza e de liberdade de Kant, significa afirmar que ele assume, juntamente com a Estética transcendental, o primordial da terceira antinomia, em relação à qual Kant trabalha a partir da consideração de que uma "solução" só poderia ser encontrada pelo Idealismo Transcendental. A ideia transcendental da liberdade seria o autêntico fundamento das ações e o arbítrio humano é denominado arbitrium liberum, dado que a sensibilidade, em certa medida, não tornaria sua ação necessária, já que o homem possui a capacidade de determinar-se por $\mathrm{si}^{15}$. Na esfera desta antinomia, $\mathrm{o}$ pensador supõe, por conseguinte, que todo o campo da experiência seja transformado em um conjunto da mera natureza. Apesar de não ser possível a obtenção de uma totalidade absoluta das condições na relação causal, a razão dispõe da ideia de uma espontaneidade que pode, por si mesma, iniciar uma ação sem a necessidade de antepor-lhe uma causa e, a partir disso, seria possível afirmar que o conceito prático de liberdade se funda sobre a ideia transcendental dela mesma, conforme exposto na nona seção da Antinomia da razão pura ${ }^{16}$, isto é, a liberdade transcendental teria de ser pensada para que a liberdade prática também fosse. Se os fenômenos tornam todas as ações necessárias, a supressão da liberdade transcendental aniquilaria, concomitantemente, toda a liberdade prática. 0 fato de haver uma forte determinação causal no fenômeno não anularia, pois, a causalidade do arbítrio que, independentemente das causas naturais, é capaz de produzir algo determinado na ordem temporal. Nesse sentido, “uma ação originária, pela qual acontece algo que

14 Idem, A 539/ B 567, p 433. grifos do autor.

15 Cf. Idem, A 533-534/ B 561-562, p.429-430. O sujeito porta um caráter empírico e está submetido à causalidade dos fenômenos, mas também tem um caráter inteligível e, por isso, não está subordinado às condições da sensibilidade. É importante notar que o terceiro conflito antinômico da razão não é um conflito de tipo lógico, já que um interesse lógico seria um interesse apenas da razão teórica, e esta não teria o aparato conceitual suficiente para resolvê-lo. Seria a razão prática que teria um interesse na antinomia e o motivo pelo qual Kant colocou tese e antítese lado a lado, sem se autoexcluírem, tinha por propósito defender uma causalidade na natureza e, por outro lado, uma causalidade por liberdade.

16 "É bastante notável que sobre essa ideia transcendental da liberdade esteja fundado o conceito prático da mesma, e que aquela constitua para este o verdadeiro momento das dificuldades que desde sempre circundaram a questão sobre a sua possibilidade" (idem, A 533/ B 561, p.430). 
não existia antes, não pode ser esperada na conexão causal dos fenômenos"17. 0 fundamento da ação, assim como o fundamento de quaisquer fenômenos, tem sempre de ser dado, segundo Kant, no pensamento, portanto no âmbito transcendental, embora nada se saiba daquilo que ele é em si. De forma muito resumida, são estes os principais elementos kantianos que Schopenhauer pressupõe paralelamente à adoção da concepção de caráter, neste momento.

Destaco, no entanto, que um "sujeito agente", tal como definido por Kant, não estaria submetido a quaisquer condições de tempo quando tomado por seu caráter inteligível. Já em relação ao seu caráter empírico,

esse sujeito estaria submetido, como fenômeno, a todas as leis da determinação segundo a ligação causal; e não seria, então, nada além de uma parte do mundo sensível cujos efeitos, como qualquer outro fenômeno, decorreriam inexoravelmente da natureza (...). No que diz respeito a seu caráter inteligível, no entanto (embora só possamos ter dele o conceito geral), o mesmo sujeito teria de ser declarado livre de toda influência da sensibilidade e da determinação por fenômenos. ${ }^{18}$

Não obstante esta ser uma das passagens determinantes a partir da qual, posteriormente, Schopenhauer se voltará contra seu mestre quanto ao papel dedutivo da razão, nesse momento o pensador parece atentar apenas para uma parte do discurso kantiano, a saber, para a indicação do status de não-determinação do caráter inteligível em relação ao empírico. Caberia, então, a pergunta: como se poderia admitir que o caráter inteligível, definido por Kant enquanto "causa dos atos dados no fenômeno", signifique o mesmo que o caráter inteligível enquanto "ato livre da vontade posto fora do tempo", tal como expressa a primeira edição de Sobre a quádrupla raiz? Esta questão se tornará mais clara quando for tomada em paralelo com a definição de caráter inteligível elaborada por Schelling, conforme tratarei no próximo tópico. Entretanto, por meio de uma insistência quanto à proximidade ou ao distanciamento em relação à definição kantiana, torna-se possível captar boa parcela do motivo pelo qual Schopenhauer toma o caráter inteligível enquanto "ato da vontade" no mesmo sentido do caráter inteligível da terceira antinomia, caso se considere o seguinte: o filósofo, ao adotar a dupla noção de caráter de Kant, frisa nela a questão da conciliação kantiana entre liberdade e necessidade. Ora, Schopenhauer também, ao conceber o caráter inteligível, visava conciliar, ao seu modo, liberdade e necessidade: para ele, porém, a liberdade diria respeito ao ato originário da vontade, o próprio caráter inteligível, e a necessidade faria parte da aparição no tempo (o caráter empírico) de todos os atos daquele "ato não-temporal". Na ordem da exposição da quádrupla raiz, no entanto, a lei que

17 Idem, A 544/ B 572, p.435.

18 Idem, A 540-541/ B 568-569, pp.433-434. 
vigora no mundo da necessidade em relação ao caráter não é mais a da causalidade, como era para Kant (enquanto causalidade por liberdade e por natureza), mas a da motivação: "o motivo é assim, para o caráter empírico, a razão suficiente do agir"19, sendo que, no entanto, a ação não resulta propriamente de motivos, mas sim do caráter empírico solicitado por estes. Uma diversidade de caracteres empíricos não seleciona os mesmos motivos diante das mesmas circunstâncias e, por isso, não se pode conhecer imediatamente o caráter empírico, mas só parcialmente na ocasião [Anlass] do encontro dele com cada motivo. Sendo assim - apesar de um mesmo caráter empírico do homem se comportar sempre da mesma forma quando posto sob a mesma influência -, nesta forma do princípio de razão suficiente (do agir), a regularidade cessa, já que, "enquanto lá [nas outras três formas do princípio de razão] permanecíamos no mundo da legalidade, aqui nos deparamos com um mundo completamente diferente, no solo da liberdade"20. Aqui, já não é mais possível que, pelo conhecimento do fundamento [Grund] nos seja dado o fundado [Begründete], pois mesmo sabendo os motivos, não saberemos qual ação do sujeito se seguirá deles.

Se, pois, o caráter inteligível é um ato de vontade que não está no tempo, já que é um "ato livre", e se "do sujeito do querer só se pode perceber o querer mesmo, não o estado que precede tal querer"'11, então a lei de causalidade não pode valer para a vontade, já que essa lei pressupõe sempre um estado anterior do qual decorre necessariamente o posterior. 0 sujeito do querer - embora seja tomado aqui apenas como um objeto ao qual ainda não se atribui um estatuto metafísico - não pode pertencer às representações que são compreendidas pela lei de causalidade, pois é "objeto imediato do sentido interno"22. Assim, a decisão depende tão somente de tal sujeito e não também daquele estado anterior. Este último só é condição do desejo; e não da decisão. Mas isso não significa que o sujeito do querer, como único objeto de uma representação imediata, não esteja submetido ao princípio de razão. Neste caso, o que passa a valer é o princípio de razão do agir, a lei da motivação. Esta seria uma espécie de "causalidade interna", vista "por dentro", já que somente por uma experiência interna se pode saber que os atos (particulares) - que constituem o próprio caráter empírico emergido do caráter inteligível - são provocados por determinados motivos cujos efeitos não podem ser apreendidos externa e mediatamente. Portanto, a lei da motivação, mesmo sendo constituída apenas pela forma do tempo puro, seria a ferramenta com a qual captaríamos a necessidade das ações que, em última instância, aduzem a algo dado fora do tempo. Nesse sentido, Schopenhauer toma as representações imediatas como "representações do sentido interno no tempo puro";

19 SCHOPENHAUER, A. Über die vierfache Wurzel des Satzes vom zureichenden Grunde. I Auflage, $\S 46$, p. 82.

20 Idem, p.83.

21 Idem, §45, p.77.

22 Idem, §44, p.76. 
e a condição para esta espécie de representação é que ela afete causalmente o corpo. Ora, o querer afeta o corpo enquanto objeto imediato, o que faz com que tal objeto (imediato) seja afetado por uma ação causal interna, sem deixar de estar exposto, como objeto entre objetos, à causalidade externa. Dessa forma, apesar de o filósofo destacar, na Dissertação de 1813, que o sujeito só pode ser conhecido como um sujeito que quer, mesmo assim esse querer é tomado como algo empírico, pois é uma representação do sujeito que afeta o sentido interno.

No fragmento 66 dos Manuscritos juvenis (escrito no mesmo ano da primeira versão de Sobre a quádrupla raiz), Schopenhauer toma a liberdade como "a capacidade do único e mesmo eu tornar-se consciente de si (de pôr-se) como temporal e espacial, ou também como não-temporal e não-espacial"23. Assim, se o caráter inteligível consiste em um "ato da vontade universal" e é livre, este "ato livre" assume a dimensão de um, por assim dizer, instante não-determinado, no qual tal caráter (não-temporal e não-espacial) se tornaria consciente de si mesmo. Se este raciocínio parece reprovável pela simples razão de que seria contraditório conceber algo não-determinado como propriedade de instante, ao mesmo tempo é possível perceber como, na sequência do referido fragmento, o próprio Schopenhauer se posiciona: "note-se que o eu, na última relação mencionada, pode ser designado somente de modo negativo: não-temporal, não-espacial; e isso se deve ao fato que a própria linguagem pertence ao temporal e ao espacial (como também o intelecto, cujos conceitos só têm significado no tempo e no espaço)"24. Mas, se mesmo assim a admissão de que tal "ato da vontade" enquanto caráter inteligível possa conhecer-se a si mesmo apresenta-se como contraditória, já que se trata de algo que o próprio autor havia condenado, então seria possível admitir que Schopenhauer se contradiz, mas somente enquanto mantém a tese de que sua concepção de caráter inteligível é exatamente a mesma daquela de Kant. Com efeito, no mesmo $\$ 46$ da Dissertação de 1813, o filósofo afirma: “mas que seja possível lançar olhares profundos sob a esfera cromática dos caracteres empíricos de um homem; que estes, subtraídos a qualquer explicação, acenem para uma compreensão imediata do caráter inteligível, percebemos nos grandes poetas, principalmente em Shakespeare"25. Entretanto, o pensador não recairia em contradição pelo fato de, na primeira edição da Dissertação, deduzir - de modo semelhante a Kant - o caráter inteligível (se não como fundamento, ao menos como "estado permanente") a partir do caráter empírico. Isso só teria ocorrido se Schopenhauer não tivesse tomado tal caráter inteligível (kantiano) como “ato de vontade". Mas, trata-se, sim, de uma assimilação ou de uma interpretação;

23 SCHOPENHAUER, A. Der Handschriftliche Nachlass. Die Genesis des Systems, §66, p.35.

24 Idem, ibidem.

25 SCHOPENHAUER, A. Über die vierfache Wurzel des Satzes vom zureichenden Grunde. I Auflage, $\S 46$, p.83. 
e a dedução do mencionado "estado permanente" não é operada pela mesma lei de causalidade kantiana, mas, conforme expus acima, pela lei da motivação.

No contexto de Sobre a quádrupla raiz de 1813, no qual esta última questão aparece de um modo mais enfático, isto é, na indicação do sujeito do querer e da lei da motivação, sobressaem-se algumas dimensões tanto de proximidade quanto de distanciamento em relação à doutrina kantiana: “admissão de um estado permanente do sujeito da vontade, do qual as suas decisões seguem-se de modo necessário"26, ou então um "sujeito do querer cuja vontade não é determinada a partir de nada (...) e que se trata apenas de um querer, em sua natureza livre ao máximo grau, que constitui a essência mais íntima do homem, independente de tudo o resto"27. Dessa forma, este é o modo pelo qual Schopenhauer acredita deduzir o caráter inteligível: admite-se um tal "sujeito do querer" que, antes de tudo, "é conhecido somente enquanto um sujeito que quer (em cada ato de vontade), não em um estado que preceda o próprio querer" 28 . O conhecimento do "sujeito que quer" estaria submetido a esse "estado precedente", e o fato de que tal sujeito deseje isto ou aquilo, ou é simplesmente casual, ou então segue uma regra. Ora, se, conforme mostrei acima, a observação dos efeitos do querer que se tornam causais (o próprio agir) atesta que, diante dos mesmos motivos, um indivíduo comporta-se de um modo e um outro de outro modo, mas que a mesma pessoa, em condições idênticas, tem os mesmos comportamentos, então é preciso admitir que existe uma "regra" no sentido de "um estado permanente do sujeito do querer"29. Quanto ao caso de o referido "ato de vontade" ser também livre e, por conseguinte, toda a responsabilidade de cada sujeito já residir nele, Schopenhauer deduz do fato de que cada um, ao passo que age da mesma forma sob iguais circunstâncias, tem, "todavia, a viva consciência de que poderia ter agido de maneira completamente diversa, desde que tivesse querido; ou seja, que a sua vontade não é determinada por nada de estranho e que aqui não se trata de um poder, mas apenas de um querer, em sua natureza livre ao máximo grau" 30 . É importante observar que, nesta primeira versão da Dissertação, o pensador toma os atos de vontade, por meio dos quais o sujeito do querer é conhecido e que se seguem do mencionado "ato livre", numa relação de causalidade com as ações do corpo, pois "agir não é querer, mas sim um efeito do querer tornado causal" 31 . Diferentemente disso, na primeira edição de 0 mundo como vontade e como representação e na segunda edição de Sobre a quádrupla raiz, ações corporais e vontade são idênticas e, assim, agir e querer também são a mesma

26 Idem, p.80, grifo meu.

27 Idem, ibidem, grifos meus.

28 Idem, p.79, grifo do autor.

29 Idem, p. 80.

30 Idem, ibidem, grifos do autor.

31 Idem, §44, p.76. 
coisa $^{32}$.

Vale notar, então, como Schopenhauer já interpreta à sua maneira a antinomia kantiana da liberdade. Kant cunha sua liberdade transcendental pela defesa de que um sujeito (transcendental) seria capaz de começar por si mesmo, por uma "espontaneidade absoluta das causas" e por sua capacidade de agir por liberdade, uma série de fenômenos ${ }^{33}$. Schopenhauer admite uma "viva consciência" (por parte do sujeito do querer) de que poderia ter agido de maneira completamente diversa desde que tivesse querido. Mas aqui o pensador ainda não polemiza contra a "tese" do terceiro conflito antinômico de seu mestre, como acontecerá em outros momentos mediante uma censura à aplicação da causalidade para além do âmbito fenomênico. Isso significa que, na Dissertação de 1813, mesmo já conhecendo a mencionada crítica cética de seu professor Schulze, Schopenhauer não critica diretamente a causalidade por liberdade, muito embora o tema da necessidade com que ocorrem todas as nossas representações seja o alvo da Dissertação, e que, nesse sentido, o autor cobre um maior rigor de Kant quanto à lei de causalidade. Pelas considerações que destaquei acima, é possível afirmar que se trataria, ao menos em alguma medida, da indicação schopenhaueriana de certas diferenças entre o "sujeito do querer" e o "caráter inteligível” (este nos moldes kantianos). É curioso, no entanto, que, se na Dissertação de 1813, essas diferenças não foram especificadas textualmente pelo pensador, no conhecido escrito do ano anterior, intitulado Zu Kant (de março de 1812), Schopenhauer já havia se posicionado de forma polêmica nesse assunto contra o filósofo do idealismo crítico. Neste escrito, a crítica (que será amplificada nos Cadernos de estudos de 1817 e principalmente no Apêndice de 0 mundo como vontade e como representação, de 1818) já é endereçada ao fato de Kant ter igualado sob o mesmo nome de "razão" a determinação das condições da experiência e a faculdade de tirar conclusões com o "fundamento de nosso ser", que está acima da experiência e da natureza sensível (razão teórica e razão prática) ${ }^{34}$. Assim, o alvo da crítica de 1812 é a possibilidade de se estabelecer a priori uma regra para as ações humanas, mas com isso tal crítica se estende também à concepção kantiana de caráter inteligível, pois é a esta que, em última instância, o dever incondicionado se remete, no âmbito da causalidade da razão. Mesmo assim, não é difícil notar como,

32 É importante frisar que esta tese é uma das que será substancialmente modificada na edição da Dissertação de 1847. Nesta segunda edição de Sobre a quádrupla raiz, baseado na total identificação entre corpo e vontade, que já havia sido desenvolvida em sua obra magna, Schopenhauer não falará mais de uma causalidade do querer sobre o agir. Nesta versão do escrito sobre o princípio de razão, as ações ou os movimentos do corpo significarão o mesmo que um grau de vontade objetivada.

33 Cf. KANT, I. Crítica da razão pura, A 446/ B 474, p.378-379.

34 “A priori manifesta-se para mim, e não de uma vez por todas, mas em cada caso, que eu deva agir dessa forma e não de outra. A isso Kant chama de razão prática (...). Ora, ao nome razão teria de pertencer tanto o sentido teorético quanto o sentido prático. A linguagem alemã, no entanto, concede a ele apenas a acepção teórica; e, assim, designa-o com maior clareza e habilidade de entendimento" (SCHOPENHAUER, A. Der Handschriftliche Nachlass. Zu Kant, pp.302-304). 
neste período, esta distância em relação à doutrina kantiana ainda não está bem delimitada, ou melhor, como vontade e caráter inteligível são, aqui, tomados a partir dos mesmos critérios ou até mesmo como idênticos: em um fragmento póstumo dessa época, o filósofo afirma que "o corpo humano nada mais é do que vontade tornada visível. A forma de todo objeto é o tempo. A própria vontade, o caráter inteligível permanece; caso contrário, ele seria apenas visibilidade [Sichtbarkeit] e não o que se torna visível" 35 . Diante disso, podemos afirmar que a vontade que, aqui, aparece em seu acento humano, é identificada com o caráter inteligível porque o hiato entre ela e o conhecimento ainda não havia surgido em definitivo ${ }^{36}$.

A vontade, neste momento, é tomada às custas do sujeito do querer no âmbito da lei da motivação, no qual também ainda não se admite com muita clareza a possibilidade de uma identidade entre conhecedor e conhecido. 0 "eu quero" é uma proposição sintética a posteriori dada por uma experiência interna (somente no tempo), "provavelmente a mais antiga entre todas as proposições de experiência presentes em cada consciência, com a qual inicia-se o conhecimento" ${ }^{37}$, mas tal "Eu" ainda não ecoa em um universo cosmológico. Nesse sentido, uma passagem do $\$ 43 \mathrm{da}$ primeira edição de Sobre a quádrupla raiz chama particularmente a atenção quando se percebe que, em sua segunda versão (\$42), é reformulada com um acréscimo, a meu ver, determinante. Pouco antes de admitir a possibilidade, embora ainda de forma pouco elaborada, da identidade entre quem conhece e quem é conhecido, Schopenhauer, em 1813, afirma: “mas a identidade do sujeito do querer com o sujeito cognoscente, graças à qual (isto é, necessariamente) a palavra 'Eu' inclui e designa a ambos, é absolutamente inconcebível"38, já que só se pode conceber relações entre objetos. Esta mesma passagem, em sua segunda versão, é elaborada da seguinte forma: "mas a identidade do sujeito do querer com o sujeito cognoscente, em virtude da qual (e necessariamente) a palavra 'Eu' inclui e designa a ambos, é o nó cósmico e por isso inexplicável"39. Quando o autor, em seguida, considera o fato de que, para tal identidade, não valem mais as regras para o conhecimento dos objetos e, por isso, uma efetiva união entre sujeito e objeto é imediatamente dada, diz - em 1813 que aquele que tenha bem presente a impossibilidade de conceber [Unbegreifliche], e - em 1847 - a impossibilidade de explicar [Unerklärliche] tal identidade, poderá

35 SCHOPENHAUER, A. Der Handschriftliche Nachlass. Die Genesis des Systems, §191, p.106, grifos meus. Sobre este tópico, Cacciola também afirma: "Esta vontade, como ser próprio, ainda não se distingue completamente do caráter inteligível de Kant, cuja manifestação fenomênica é o caráter empírico" (CACCIOLA, M. L. Schopenhauer e a questão do dogmatismo. São Paulo: Edusp, 1994, p.103).

36 Cf. CACCIOLA, M. L. Schopenhauer e a questão do dogmatismo, p.102.

37 SCHOPENHAUER, A. Über die vierfache Wurzel des Satzes vom zureichenden Grunde. I Auflage, $\S 43$, p.76.

38 Idem, ibidem, grifos meus.

39 Idem, ibidem. 
denominá-la - tanto em 1813 quanto em 1847 - de kat) exocðhn, “o milagre”. Ou seja, nos dois momentos de sua filosofia, o pensador apresenta o mesmo princípio segundo o qual a lei de causalidade não pode valer para o caso da experiência interna; aquela é apenas a forma do princípio de razão na primeira classe de objetos, ou seja, no mundo material dado na intuição externa, no qual uma ação é impensável sem a influência de um motivo. Já o caso do âmbito interno dos processos de decisão permanece, quando tomado deste ponto de vista (da intuição externa), um mistério. Tanto em 1813 quanto em 1847, o autor admite, porém, que isso não se aplica às experiências internas, a partir das quais o corpo é objeto imediato do querer, âmbito em que, ao indagarmos o "porquê" das decisões, temos a "viva consciência" de que elas não podem resultar de nenhum dos estados de representações das três classes anteriores, mas que dependem imediatamente somente do sujeito do querer, de quem só se pode perceber o querer mesmo. No entanto, a significativa diferença se dá quando esta consideração, para além do plano da causalidade, é, contudo, imaginada ao menos sob uma regra e, em 1813, se diz - caso se tome o ponto de vista da lei de causalidade - que isso seria absolutamente impossível, enquanto que, em 1847, quando a Vontade cósmica há muito já foi definida como o princípio irracional do mundo e, com isso, não mais se confunde com o conhecimento causal, tal questão não é mais inconcebível, mas, no máximo, seria inexplicável, um nó cósmico do mundo que não pode ser decifrado pela lei de causalidade.

Ademais, o tema da adoção (parcial ou integral) da linguagem kantiana quanto ao caráter inteligível salta aos olhos quando se considera que Schopenhauer, na segunda versão de Sobre a quádrupla raiz, abole completamente o §46, cujo título era justamente Motivo, decisão, caráter empírico e caráter inteligível. Se, em 1813, o filósofo filia-se bastante estreitamente a Kant (assim como a Schelling, conforme indicarei a seguir) quanto a este tema, contrariamente a isso, em 1847, após abordar a lei da motivação e a vontade percebida em nós mesmos como pedra de toque de toda a sua metafísica, Schopenhauer remete o leitor ao seu escrito premiado, de 1839, Sobre a liberdade da vontade, “onde - escreve o filósofo - tudo isso é tratado em pormenores" 40 . É importante frisar, então, como esse direcionamento exemplifica o método com o qual o filósofo, em 1847, reelabora seu escrito sobre o princípio de razão sob a luz de tudo o que havia produzido até então, ou seja, de praticamente todo o seu sistema. Ao remeter o leitor a tal escrito, o pensador também indica, de forma discreta, - principalmente mediante a expressão que considera "a capacidade de conhecimento dos indivíduos" - que a sua concepção de caráter (no percurso filosófico entre 1813 e 1847) havia sido reconsiderada. Em Sobre a liberdade da

40 "Quanto ao modo e a necessidade do efeito dos motivos, o seu ser condicionado pelo caráter empírico, individual, assim como pela capacidade de conhecimento dos indivíduos etc, remeto à minha obra premiada sobre a liberdade da vontade" (SCHOPENHAUER, A. Über die vierfache Wurzel des Satzes vom zureichenden Grunde. II Auflage, §43, p.253). 
vontade, Schopenhauer frisou o caráter não apenas como imutável, não-temporal (enquanto inteligível) e fragmentário (enquanto empírico), mas, no caso do homem, como individual, empírico, invariável e inato ${ }^{41}$. Isto é, a adoção kantiana teria continuado presente, mas particularmente reconsiderada pela própria ideia de que, como frisa na conclusão, “o caráter é a essência empiricamente reconhecida [empirisch erkannte], constante e imutável de uma vontade individual"42.

\section{O caráter como ato de vontade: a leitura da noção schellinguiana de caráter inteligível}

Embora com diferentes intenções e perspectivas, Schopenhauer leu e releu atentamente as obras de Schelling em praticamente todos os períodos de sua produção filosófica, desde os anos universitários até a publicação (em 1851) dos Parerga e paralipomena. Se tais leituras foram retomadas durante o percurso em que sua filosofia se solidificou, antes de 1818 o pensador já detinha um conhecimento quase completo da doutrina schellinguiana, cuja presença ou afinidade é identificada nos primeiros escritos do pensador, mas de modo bastante enfático na caracterização da noção de vontade. No entanto, diante das posteriores inumeráveis inventivas de Schopenhauer contra este seu mestre - principalmente pela inclusão de seu nome na classe dos "filosofastros" - muitos olhares sobre as relações entre as duas filosofias não tendem a tomar o tom schellinguiano da filosofia schopenhaueriana como uma importante contribuição, mas antes como um erro a ser esquecido ${ }^{43}$. Para além da tendência desses olhares, assim como para além da trivial noção de "influência”, permanecem as similaridades diante (de muitas) das quais é difícil não conceder o primado a Schelling: a ideia da Stufenfolge, segundo a qual a natureza estaria organizada, para ambos, em uma sucessão ascendente de formas cada vez mais complexas; e a própria concepção de "filosofia da natureza" como uma espécie de síntese entre conhecimento científico e verdade metafísica em Schopenhauer, guardam um estreito parentesco com a Naturphilosophie schellinguiana.

41 Cf. SCHOPENHAUER, A. Über die Freiheit des Willens. In: Sämtliche Werke. Bd. III. München: Piper Verlag, 1911-1941, pp.518-526.

42 Idem, p. 565.

43 Importantes estudos recentes não consideram esta avaliação e reconhecem a ampla e não circunscrita presença de Schelling no pensamento schopenhaueriano. Dentre tais estudos, podemos citar: a) VECCHIOTTI, I. Schopenhauer e Schelling: problemi metodologici e problemi di contenuto. Schopenhauer Jahrbuch, Würzburg, Bd. 68, 1987, pp.82-108; b) KOSSLER, M. Empirischer und intelligibler Charakter. Von Kant über Fries und Schelling zu Schopenhauer. Schopenhauer Jahrbuch, Würzburg, Bd. 76, 1995, pp.195-201; c) HÜHN, L. Die intelligible Tat. Zu einer Gemeinsamkeit Schellings und Schopenhauers. In: IBER, C.; POCAI, R. (Hrsg.). Selbstbesinnung der philosophischen Moderne. Beiträge zur kritischen Hemeneutik ihrer Grundbegriffe. Würzburg: Königshausen \& Neumann, 1998, pp.55-94; d) BARBOZA, J. Infinitude subjetiva e estética: natureza e arte em Schelling e Schopenhauer. São Paulo: Unesp, 2005; e) BARBERA, S. Schopenhauer und Schelling. Aufzeichnungen über den Begriff der Entzweiung des Willens. In: CIRACİ, F.; FAZIO, D.; KOSSLER, M. (Hrsg.). Schopenhauer und die Schopenhauer-Schule. Würzburg: Königshausen \& Neumann, 2009, pp.73-88. 
Sem a pretensão de aprofundar aqui o mérito e as nuances de tais relações, é determinante que, em vista da temática deste artigo, seja destacado o inegável fato de Schopenhauer ter considerado, às expensas do idealismo kantiano, a noção de caráter (inteligível) tal como elaborada por Schelling. Assim, somando-se às duas questões mencionadas acima enquanto presença schellinguiana em Schopenhauer, o querer como "ser originário", indicado por Schelling em seu escrito sobre a liberdade (1809), não comparece apenas na caracterização geral e oscilante da noção schopenhaueriana de vontade, mas também e mais especificamente na aqui tratada noção de caráter. Na já citada passagem da primeira edição de Sobre a quádrupla raiz, Schopenhauer não diferencia o caráter inteligível, definido por Schelling, em relação àquele da filosofia kantiana. A “apreciável exposição” schellinguiana, apesar de ser tomada apenas como “ilustrativa” em relação à de Kant ${ }^{44}$, é acatada paralelamente à adoção do caráter inteligível do âmbito da Dialética transcendental.

Schopenhauer não teria, com isso, faltado com a justiça em relação a Schelling se considerarmos a advertência deste último, nas Investigações filosóficas sobre a essência da liberdade humana: "não reproduzimos o conceito kantiano [de caráter inteligível] com as suas próprias palavras, mas tal como achamos que ele haveria de exprimi-lo na tentativa de torná-lo compreensível" ${ }^{45}$. Schelling está convicto de que sua concepção de caráter inteligível só não é a mesma em relação àquela de Kant no que se refere ao emprego das palavras, o que se revela uma confissão de fidelidade ao idealismo transcendental com o fito de expressá-lo mais claramente ${ }^{46}$. Nesse sentido, a noção de caráter acaba sendo uma espécie de critério mediante o qual se torna possível perceber como tanto o pensamento schopenhaueriano quanto o schellinguiano estão cravados no idealismo crítico e diferenciam-se dele só na medida em que empreendem "duas variantes” de exposição da mesma doutrina da liberdade. No caso de Schelling (que considera o idealismo kantiano como a única corrente "que foi capaz de elevar a doutrina da liberdade à única região em que ela se faz compreensível (...), por ter considerado que a essência inteligível de cada coisa, e sobretudo do homem, encontra-se tanto fora de qualquer nexo causal como fora e acima do tempo" ${ }^{47}$ ), uma tal variante pode ser identificada na afirmação de

44 SCHOPENHAUER, A. Über die vierfache Wurzel des Satzes vom zureichenden Grunde. I Auflage, $\S 46$, p. 80 .

45 SCHELLING, F. W. J. A essência da liberdade humana: Investigações filosóficas sobre a essência da liberdade humana e das questões conexas. Tradução de Márcia de Sá Cavalcante. Petrópolis: Vozes, 1991, p.60.

46 Diante desta admissão e reconhecimento de Schelling em relação a Kant, é difícil não lembrar da conhecida passagem de Sobre o fundamento da moral na qual Schopenhauer acusa Schelling de desonestidade por este ter se apropriado dos resultados do idealismo kantiano sem citar a fonte. Neste último caso, diferentemente do que se tem na Dissertação de 1813, uma injustiça teria sido cometida (Cf. SCHOPENHAUER, A. Sobre o fundamento da moral. Tradução de Maria Lúcia Cacciola. São Paulo: Martins Fontes, 2001, p.95).

47 SCHELLING, F. W. J. A essência da liberdade humana, p.59-60. 
que uma "essência inteligível" do homem, "agindo de forma pura e simplesmente livre e absoluta, (...) é essencialmente seu próprio ato" ${ }^{48}$. Nesta concepção, liberdade e necessidade permanecem entrelaçadas como uma única essência que só pode aparecer como divergente (como uma ou outra) quando observada por diferentes lados ${ }^{49}$. Quando se admite que o eu é o seu próprio ato, a sua consciência é a "autoposição", o colocar-se a si mesmo [Selbstsetzen], conforme o pensador explica:

Mas o eu não difere da consciência, sendo o próprio colocar-se a si mesmo [Selbstsetzen]. Essa consciência, porém, na medida em que é pensada meramente como apreensão de si mesma ou conhecimento do eu não é o primeiro termo e já pressupõe, como todo simples conhecimento, o ser em sentido próprio. Esse ser suposto antes do conhecimento não é, todavia, nenhum ser se ao mesmo tempo não é conhecimento. É um real colocar-se a si mesmo, uma vontade primordial e originária que constitui a si mesmo como algo e que consiste no fundamento e na base de toda essencialidade (...) Por mais inapreensível que essa ideia possa se apresentar para o senso comum, todo ser humano carrega consigo um sentimento com ela compatível de que, desde sempre, ele é o que é e não algo que se tornou no tempo ${ }^{50}$.

Nesta passagem encontram-se os elementos com os quais Schelling acredita poder conciliar liberdade e necessidade. Essa conciliação seria possibilitada pela admissão de que o ser que precede a consciência é um "querer originário", sendo que a mencionada Selbstsetzen, a "autoposição" da consciência, seria uma "decisão posta fora do tempo". O homem "decidiria", pois, por uma essência mediante um "ato de autoposição", um colocar-se a si mesmo que se tornaria o próprio "eu”, "pois esse ato antecede a consciência e a essência (o ser) na medida em que os faz" ${ }_{51}$. Assim, a fórmula seria (embora somente neste sentido) esse sequitur operari, uma vez que, observando-se as palavras do próprio autor, "essa necessidade interior é justamente a liberdade" ${ }^{52}$. O esse seguiria o operari porque se "autoporia" livremente: "o ato pelo qual sua vida [do homem] se determina no tempo não pertence ao tempo, mas à eternidade" ${ }_{53}$. Mas os atos que se seguem a esse ato originário são necessários, já que se remetem a uma essência (inteligível); e, neste sentido, operari sequitur esse. Em verdade, com este raciocínio, Schelling explica que pretende visar o sentimento que todo ser humano carrega segundo o qual ninguém torna-se algo no tempo, mas

48 Idem, pp.60-61, grifos do autor.

$49 \mathrm{Na}$ sequência da exposição desta tese, Schelling traz uma referência direta à concepção fichteana

de "eu": "o eu, diz Fichte, é o seu próprio ato. A consciência é o colocar-se de si mesmo" (idem, p.61).

50 Idem, p.61 [tradução modificada], grifos meus.

51 Idem, p.62, grifo do autor.

52 Idem, p.61.

53 Idem, ibidem. 
"se é o que se é", o que leva à defesa de que ninguém é bom ou mau de forma contingente ou arbitrária.

As semelhanças com Schopenhauer residiriam, então, na própria doutrina do caráter inteligível enquanto este é tomado como ato originário da vontade, livre porque é um "ato de vontade posto fora do tempo". Com efeito, em um fragmento póstumo de 1814 (escrito em Dresden), Schopenhauer afirma: “chamei de caráter inteligível um ato de vontade que está fora do tempo, cujo desenvolvimento é a vida no tempo ou caráter empírico" ${ }^{54}$. Pelas mesmas sendas schellinguianas, Schopenhauer reconhece (como já mencionei) a liberdade em tal ato originário e a necessidade naquilo que dele se segue. Os motivos determinam necessariamente o querer em relação ao caráter inteligível exposto no caráter empírico. Por esta via, chega-se à consideração da necessidade das ações que, na composição da Dissertação de 1813, tem como diretriz a quarta modalidade do princípio de razão suficiente. Mas, se a necessidade exaure todo o campo das ações decorrente do "ato primordial", este permanece livre. Promove-se, então, um encontro entre liberdade e necessidade na consciência de um mesmo sujeito que, nesse sentido, toma para si toda a responsabilidade de seus atos, já que - tanto em Schelling quanto em Schopenhauer - alguém é como é por culpa própria e, na ocasião de uma ação injusta, teria consciência de que seria impossível agir de outra forma. Segundo Schelling, "o fato de Judas ter traído Cristo não poderia ter sido alterado nem por ele mesmo e nem por qualquer outro (...). Ele não traiu Cristo sob pressão, mas por sua vontade e com plena liberdade" ${ }^{55}$. É que a visão schellinguiana reconhece que na consciência de cada homem permanecem traços daquele ato originário, o que se pode verificar quando alguém, “para se desculpar com relação a uma má ação, diz: “é assim que eu sou' (...), sabendo que the teria sido impossível agir de outro modo" ${ }_{56}$. De forma semelhante, Schopenhauer defende que alguém teria "a viva consciência de que poderia ter agido de modo completamente diferente, desde que tivesse querido" ${ }^{57}$, mas como a "essência mais íntima do homem" - o querer como fruto de um ato de vontade - foi assim definido, aquela possibilidade está descartada.

Assim, da convergência destes dois pensamentos pode-se colher principalmente a questão do reconhecimento da regência da necessidade no âmbito das ações, assim como a questão da localização da moralidade na esfera da liberdade. Este tópico é um dos critérios que une Schelling e Schopenhauer como herdeiros da mesma fortuna kantiana da imutabilidade do caráter. Mais importante ainda é notar como a perspectiva da leitura de Kant empregada por Schopenhauer em Sobre a quádrupla

54 SCHOPENHAUER, A. Der Handschriftliche Nachlass. Die Genesis des Systems, §241, p.142.

55 SCHELLING, F. W. J. Sobre a essência da liberdade humana, p.62.

56 Idem, ibidem.

57 SCHOPENHAUER, A. Über die vierfache Wurzel des Satzes vom zureichenden Grunde. I Auflage, §46, p.79. 
raiz de 1813 ainda não havia permitido ao autor realizar a conhecida recusa ao essencial da noção kantiana de caráter inteligível enquanto fruto de uma dedução. Isso somado à assimilação quase acrítica da ideia de caráter inteligível de Schelling faz-nos reservar a imagem de um Schopenhauer polêmico com seus mestres para o período posterior à elaboração detalhada de sua metafísica da vontade, notadamente a partir de sua obra magna. Constatações como esta justificam a observação dos períodos nos quais Schopenhauer assimilou, criticou ou se opôs a filósofos com os quais dialogava, caso da análise aqui pretendida sobre alguns aspectos da assimilação do idealismo transcendental e de Schelling no período juvenil do pensador, o que a sua recepção das noções de caráter inteligível e de caráter empírico permite ilustrar.

\section{Referências}

BARBERA, S. Schopenhauer und Schelling. Aufzeichnungen über den Begriff der Entzweiung des Willens. In: CIRACì, F.; FAZIO, D. M.; KOSSLER, M. (Hrsg.). Schopenhauer und die Schopenhauer-Schule. Würzburg: Königshausen \& Neumann, 2009, pp.73-88.

BARBOZA, J. Infinitude subjetiva e estética: natureza e arte em Schelling $e$ Schopenhauer. São Paulo: Unesp, 2005.

CACCIOLA, M. L. Schopenhauer e a questão do dogmatismo. São Paulo: Edusp, 1994. HÜHN, L. Die intelligible Tat. Zu einer Gemeinsamkeit Schellings und Schopenhauers. In: IBER, C.; POCAI, R. (Hrsg.). Selbstbesinnung der philosophischen Moderne. Beiträge zur kritischen Hemeneutik ihrer Grundbegriffe. Würzburg: Königshausen \& Neumann, 1998, pp.55-94.

KANT, I. Kants Gesammelte Schriften. Preussischen Akademie der Wiessenschaften. Berlin: Walter de Gruyter. Bd. I-IX, 1902-1923.

.Crítica da razão pura. $3^{\mathrm{a}}$ ed. Trad. Fernando Costa Mattos. Petrópolis: Vozes; Bragança Paulista: Ed. São Francisco, 2013.

KOSSLER, M. Empirischer und intelligibler Charakter. Von Kant über Fries und Schelling zu Schopenhauer. Schopenhauer Jahrbuch, Würzburg, Bd. 76, 1995, pp.195-201.

SCHELLING, F. W. J. A essência da liberdade humana: Investigações filosóficas sobre a essência da liberdade humana e das questões conexas. Tradução de Márcia de Sá Cavalcante. Petrópolis: Vozes, 1991.

SCHOPENHAUER, A. Sämtliche Werke. Edição hitórico-crítica de Paul Deussen. 16 Bd. München: Piper Verlag, 1911-1941. In: "Schopenhauer im Kontext III" - Werke, Vorlesungen, Nachlass und Briefwechsel auf CD-ROM (Release 1/2008). 
Über die vierfache Wurzel des Satzes vom zureichenden Grunde. Auflagen I und II. Bd. III. In: Sämtliche Werke. München: Piper Verlag, 1911-1941. . Über die Freiheit des Willens. In: Sämtliche Werke. Bd. III. München: Piper Verlag, 1911-1941.

. Der Handschriftliche Nachlass. In: Sämtliche Werke. Bd. XI. München: Piper Verlag, 1911-1941.

- Sobre o fundamento da moral. Tradução de Maria Lúcia Cacciola. São Paulo: Martins Fontes, 2001.

. O mundo como vontade e como representação. Tomo I. Tradução de Jair Barboza. São Paulo: Unesp, 2005.

VECCHIOTTI, I. Schopenhauer e Schelling: problemi metodologici e problemi di contenuto. Schopenhauer Jahrbuch, Würzburg, Bd. 68, 1987, pp.82-108. 